\title{
Influence of Plasma Nitriding Process in Wear Strength of the F53 Superduplex Stainless Steel
}

\author{
J. O. Pereira Neto ${ }^{1}$, R. O. Silva ${ }^{1}$, E. H. Silva ${ }^{2}$, J. A. Moreto ${ }^{3}$, L. S. Rossino ${ }^{1,4}$, M. D. Manfrinato ${ }^{1}$ \\ ${ }^{I}$ Sorocaba Technological College (FATEC), Sorocaba/SP - Brazil \\ ${ }^{2}$ Belgian Nuclear Research Centre - SCK-CEN - Belgium \\ ${ }^{3}$ Federal Institute Goiano (IF Goiano), Morrinhos/GO - Brazil \\ ${ }^{4}$ Federal University of São Carlos (UFSCar), Sorocaba/SP - Brazil
}

\begin{abstract}
In an attempt to improve a surface of super-duplex stainless steel was carried out ion plasma nitriding. The super-duplex stainless steel was nitriding by plasma process during 2 hours at the $350-570^{\circ} \mathrm{C}$. As can be seen, the thermochemical treatment influenced the microhardness superficial due to kind of nitride formed. The microwear resistance decreased at $400^{\circ} \mathrm{C}$ due to formation different nitrides in surface, causing an increase in hardness and wear volume resistance.
\end{abstract}

Keywords: plasma nitriding, super-duplex stainless steel, microwear

\section{Introduction}

The materials used in petrochemical fields "off-shore", distilleries, evaporators, require a good corrosion and wear resistance [1]. The super-duplex stainless steels have been developed for applications that requiring high performance associated with high corrosion resistance; however, this material presents low wear resistance.

Ion plasm nitriding is a heat treating process that diffuses nitrogen into the surface of a metal to create a case hardened surface. It is very important to note that this process are most commonly used on low-carbon, low-alloy steels, however they are also used on medium and high-carbon steels, titanium, aluminum and molybdenum. This process form precipitates called nitrides that have excellent physical and mechanical properties such as high hardness, wear resistance, corrosion resistance, fatigue resistance and low friction coefficient. All these characteristics enhance the tribological properties of material [2].

The aim of this work was to study the resistance of super duplex stainless steel with and without plasma nitriding treatment and determine the influence of the precipitates on the surface of the material in the wear resistance.

\section{Experimental}

The material used in this investigation was the F53 stainless steel according to ASTM 189-10. Table 1 lists the chemical composition of their major elements. The chemical composition was determined by Optical Emission Spectroscopy using a Spectrometer Ametek Spectromaxx, model LMF05, situated in the laboratory of Fatec Sorocaba College.

Table 1 - Chemical Composition (w\%) of the F53 stainless steel, according to ASTM 189-10

\begin{tabular}{lllllllll}
\hline Elements & $\mathrm{C}$ & $\mathrm{Si}$ & $\mathrm{Mn}$ & $\mathrm{P}$ & $\mathrm{S}$ & $\mathrm{Cr}$ & $\mathrm{Mo}$ & $\mathrm{Ni}$ \\
\hline Nominal & $0.03 \max$ & $0.8 \max$. & $1.2 \max$. & $0.5 \max$. & $0.02 \max$. & $24-26$ & $3-5$ & $6-8$ \\
\hline Obtained & 0.029 & 0.46 & 0.99 & 0.0032 & 0.0005 & 24.6 & 3.6 & 0.32 \\
\hline
\end{tabular}

Microwear tests were carried out at the Fatec Sorocaba College Laboratory, using a microwear equipment as can be seen in Figure 1(a) with bearing steel ball AISI 52100 with $25,4 \mathrm{~mm}$ diameter that slides in contact with the surface of the material, 
causing a crater and leaving marks from the contact of two bodies as illustrated in Figure 1(b).

The microwear tests were carried out in a base material with sliding distance in function of time of $2 ; 5 ; 10 ; 15 ; 20 ; 30 ; 40$ min, rotation applying of $744 \mathrm{rpm}$ and normal load of 16 and $8.3 \mathrm{~N}$. In the thermochemical treatment material, the microwear tests were performed keeping time of 10 minutes and normal load of $16 \mathrm{~N}$ normal load. The craters were measured using a stereoscopy Olympus, model SZ61. The specimen dimensions were 30x20x10 mm.

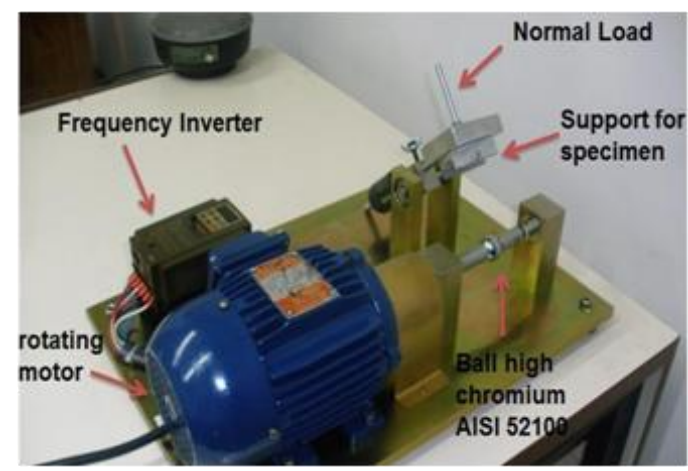

(a)

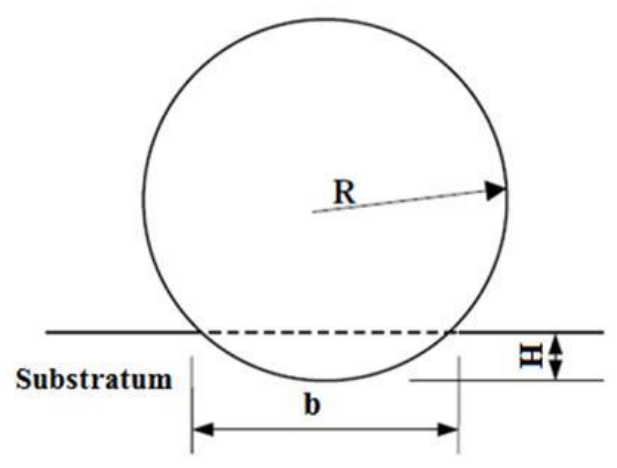

(b)

Figure 1: Schematic view of the experimental setup for microwear tests (a) fixed ball test system and (b) diagram of the sphere geometry

To determine the wear volume, quantity of sliding distance and the crater weight, were used the equations (1); (2); and (3) respectively, when $\mathrm{R} \gg>>$ b [3].

$\mathrm{V}=\frac{\pi \cdot b^{4}}{64 \cdot R}$

$C=(2 \pi \cdot \mathrm{r}) \times(\mathrm{RPM}) \times(\mathrm{t})$

$H=\sqrt{\frac{V}{\pi \cdot r}}$

The plasma ion nitriding treatment was carried out at the Federal University of São Carlos. For this, a mixture of $75 \% \mathrm{~N}_{2}$ and $25 \% \mathrm{H}_{2}$ was used for a period of 2 hours, pressure of $300 \mathrm{MPa}$, voltage of $350 \sim 400 \mathrm{~V}$ to each specimen and temperature range of $350 ; 400 ; 450 ; 500 ; 550$ and $570^{\circ} \mathrm{C}$. The X-Ray Diffraction (DRX) was used to analyze the phases formed during the thermochemical treatment, using an equipment with $40 \mathrm{kV}$ of voltage, $30 \mathrm{~mA}$ of current and molybdenum filter. The microhardness tests were performed in the metallography laboratory of Sorocaba Technological College, using a Mitutoyo equipment, model HM 220, load of $0.5 \mathrm{kgf}$ and load application time of 15 seconds.

\section{Results \& Discussion}

Average of hardness of the super duplex stainless steel is approximately " $257 \mathrm{Hv0,5"} \mathrm{without} \mathrm{thermochemical} \mathrm{treatment.}$ As can be seen in Figure 2, two-phase microstructures were revealed, where the clearer part is ferrite and the dark part is austenite.

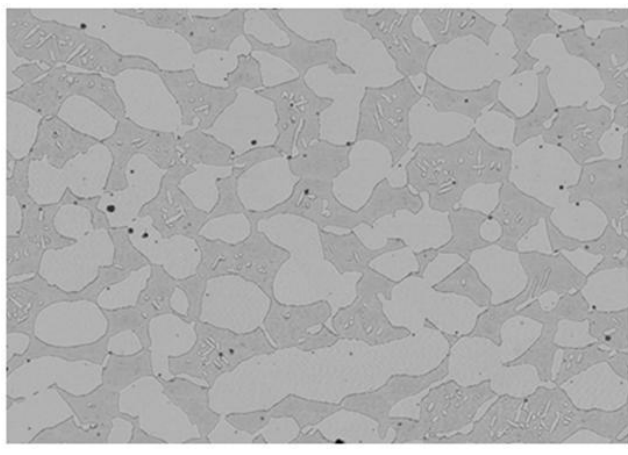

(a)

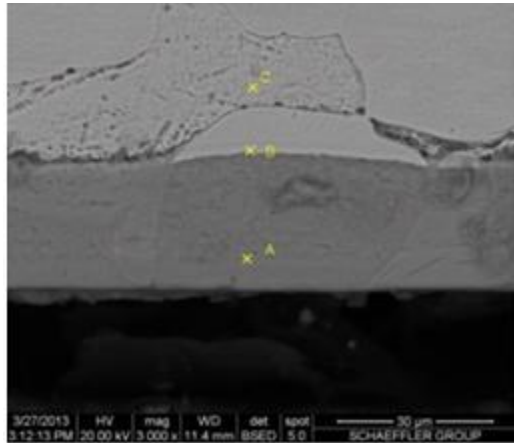

(b)

Figure 2: Metallography (a) stainless steel "F53" and (b) nitriding layer at $570^{\circ} \mathrm{C}$, attached with Beraha I reagent.

Figure 2 illustrates the nitriding layer at $570^{\circ} \mathrm{C}$. As can be seen in Figure 3 (a) the layer thickness is proportional to the 
thermochemical treatment. According to Callister [4] nitriting is a heat treating process that diffuses nitrogen into the surface of a metal to create a case hardened surface. Temperature has a most profound influence on the coefficients diffusion rates. As noted the increase of thickness layer have a higher microhardness.

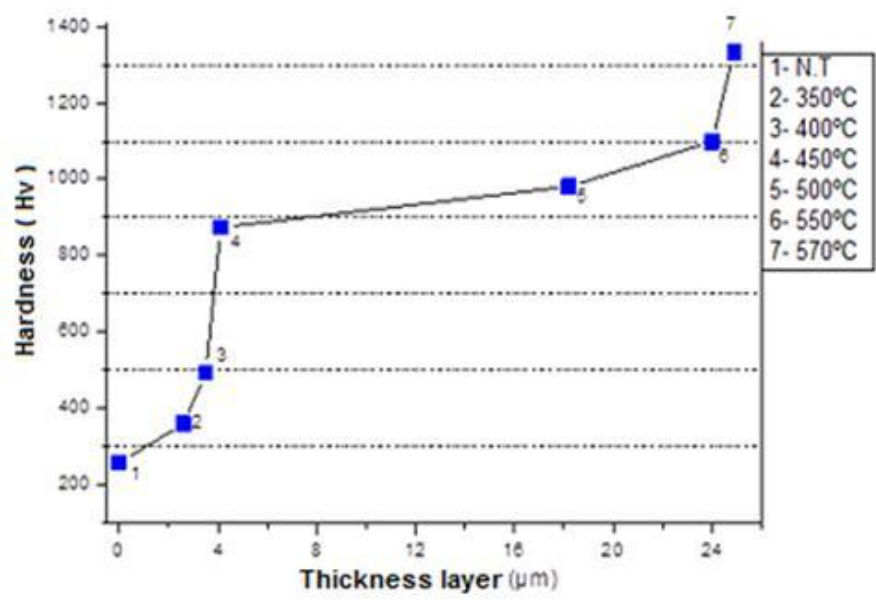

(a)

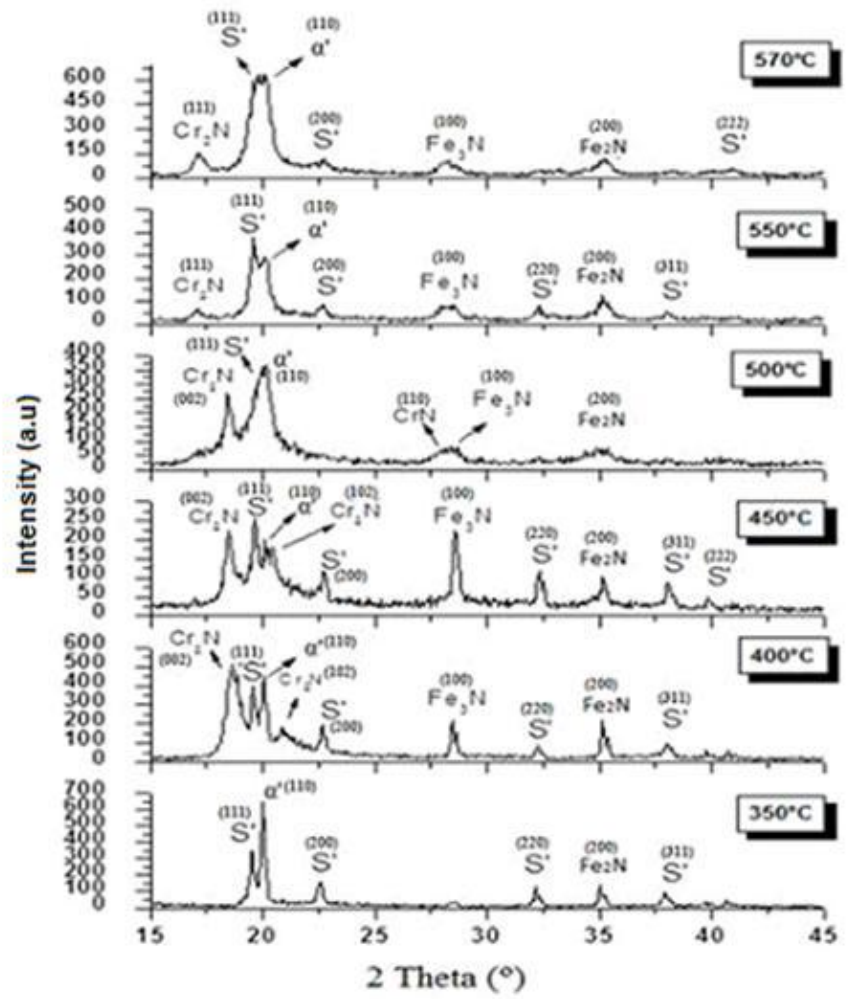

(b)

Figure 3: (a) microhardness in function depth layer nitriding, (b) X-ray diffraction at different nitriding conditions

Figure 3 (b) shows the formation of nitrides according to the thermochemical treatment. At $350^{\circ} \mathrm{C}$ exists only $\mathrm{Fe}_{2} \mathrm{~N}$ nitride and $\mathrm{S}^{\prime}$ phase formation. The $\mathrm{S}^{\prime}$ phase or expanded austenite has high hardness and this phenomena is responsible for improvements in tribological aspects. According to Christiansen [5] the presence of the interstitial element is much higher than the solubility limit results in a thermodynamically metastable and elastically distorted, which promotes a state of compressive residual stresses resulting in strong hardening, effect caused by the formation of this phase during the nitriding structure. However, the modulus of elasticity of the expanded austenite remains unchanged. This fact helps to increase the wear resistance of the material. As mentioned by Leyland and Matthews (2000) and discussed by Tschiptschin \& Pinedo (2010), the stresses on the interface substrate/coating is minimized when the value of the modulus of elasticity of the coating can be adjusted to a very close value to the substrate to obtain a better performance of system [6, 7]. At 400 ${ }^{\circ} \mathrm{C}$ observes the $\mathrm{Cr}_{2} \mathrm{~N}$ and $\mathrm{Fe}_{3} \mathrm{~N}$ nitride formation, with presence of $\mathrm{S}^{\prime}$ phase with different crystallography orientation plans. According to Tschiptschin and Pinedo [7] at this temperature occurs the formation of the S' phase, producing layers of micrometers with good mechanical properties and good corrosion resistance. The chromium nitride increases the hardness of the surface but decreases the corrosion resistance [8].

The intensity of peaks to $450^{\circ} \mathrm{C}$ are higher for the $\mathrm{Fe}_{3} \mathrm{~N}$ and $\mathrm{S}^{\prime}$ phase when compared to $400^{\circ} \mathrm{C}$ with chromium nitride presence. According to Pinedo [1], temperatures of $500^{\circ} \mathrm{C}$ and $550^{\circ} \mathrm{C}$ are most used to carry out this treatment type because they produce better thicknesses in most ferrous materials.

At $500^{\circ} \mathrm{C}$ there is a formation of a new nitride $(\mathrm{CrN})$ but with low intensity of peaks of $\mathrm{Cr}_{2} \mathrm{~N}, \mathrm{Fe}_{3} \mathrm{~N}$ and $\mathrm{Fe}_{2} \mathrm{~N}$. At $570^{\circ} \mathrm{C}$ there are a few peaks, uniformity of nitride and great thickness layer formation. The $\alpha^{\prime}$ phase appear in all Rx-diffraction. The $\alpha$ ' phase has similar characteristic of S' phase, however, presents lower capacity of nitrogen diffusion due network parameter.

Figure 4 shows that as higher the normal load higher will be the wear volume, showing severe wear with increasing of contact load. For the normal force of $16 \mathrm{~N}$, it can be seen an increase in the wear volume with increasing of sliding distance. For the normal load of $8.3 \mathrm{~N}$ can be observed an increase in volume with the sliding distance. After $1250 \mathrm{~m}$ occurs the stability of wear volume with increasing of sliding distance. According to Cozza (2006) this phenomenon has been called steady wear [9]. The best working temperature shown in Figure 4 (b) was $400{ }^{\circ} \mathrm{C}$ with less wear volume, $2.33 \times 10^{-06} \mathrm{~mm}^{3}$. This temperature increased in $99.9998 \%$ the wear resistance of super duplex stainless steel without treatment.

The resistance to wear volume is related by the phases formation, influenced by the nitriding temperature. When occurs an increase of nitriding temperature, the hardness of surface increases due the chromium nitride formation. However, the hardness increase produces a brittle layer which readily breaks reducing the wear resistance of material [10].

In addition to the decrease in wear resistance, some researchers have observed a decrease in corrosion resistance of 
stainless steel to increase the nitriding temperature due to the pauperization of chromium in solid solution caused by the formation of chromium nitrides [8].

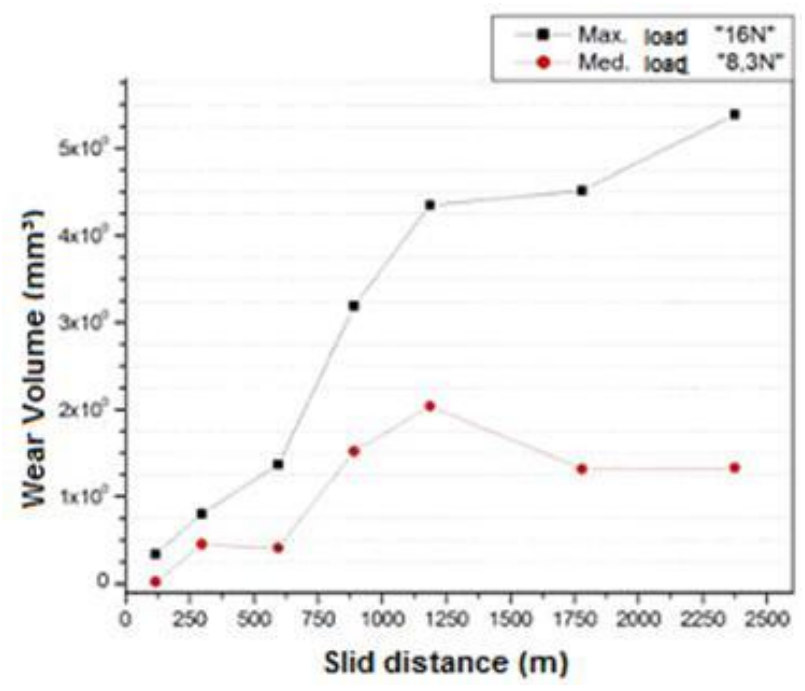

(a)

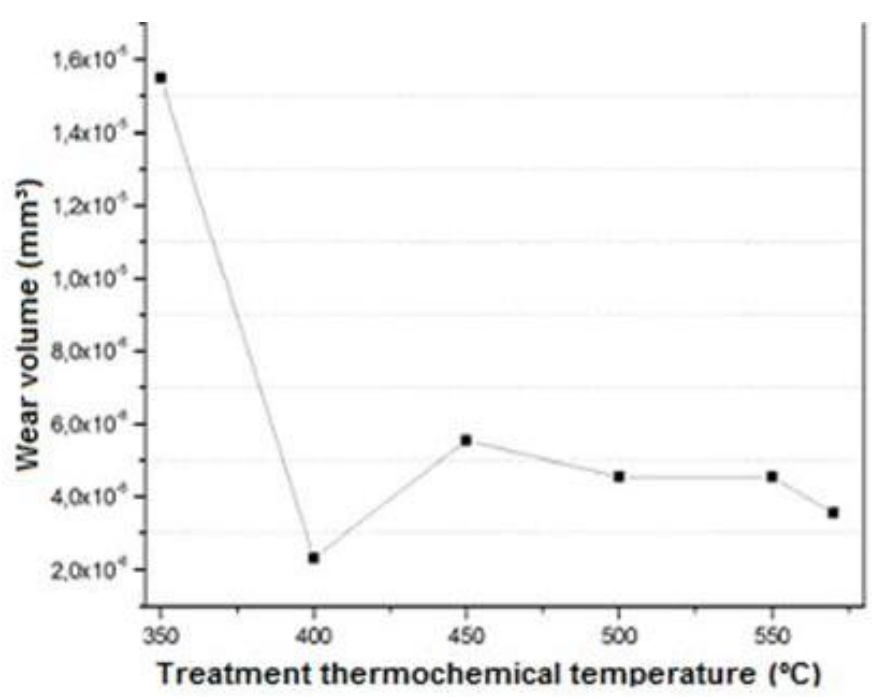

(b)

Figure 4: Wear volume (a) base material (b) thermochemical treatment

\section{Conclusions}

The super-duplex stainless steel without thermochemical treatment showed lower wear resistance when compared to the super-duplex stainless steel with thermochemical treatment.

In the $16 \mathrm{~N}$ normal load the wear volume is higher than $8.3 \mathrm{~N}$ due to strong interaction of surface contact promoted by increasing the severity of test. For the $8.3 \mathrm{~N}$ normal load condition, there was a formation of a thin oxide film which interfere drastically in the results, reducing the volume wear of material.

The treatment carried out at $350^{\circ} \mathrm{C}$ was unable to produce a thin layer of nitrogen with formation of S' phase, $\alpha$ ' and iron nitride. For temperature of $400^{\circ} \mathrm{C}$ iron, chromium nitride, $\mathrm{S}^{\prime}$ and $\alpha^{\prime}$ phases were formed and the formed layer provides better wear resistance. An increase at the nitriding temperature leads to high thickness and hardness, however, the wear resistance decreases due to chromium nitride formation. The chromium nitride promotes high surface hardness but low wear resistance.

\section{Acknowledgements}

The authors would like to thank the CAQI/IQSC/USP for Scanning Electron Microscopy Analysis.

\section{References}

1.C. E. Pinedo, Tratamento Superficial para aplicações Tribológicas. Metalurgia \& Materiais. (2004) 162-169.

2. J. C. Vendramim, Seleção de Materiais para Nitretação. ISOFLAMA Industria e Comércio de Equipamentos LTDA.

3.K. L. Rutherford and I. M. A Hutchings, Micro-abrasive wear test with particular application to coated systems. Surface and Coatings Technology. 79 (1996) p. 231-239.

4. W. D. Callister JR. Ciência e Engenharia de Materiais, LTC Livros Técnicos e Científicos, Rio de Janeiro, 2008.

5. T. Christiansen and M. A. J. Somers, On the crystallography structure of S-phase. Scripta Materialia, 50 (2004) p. 35-37.

6. A. Leyland and A. Matthews, On the significance of $\mathrm{H} / \mathrm{E}$ ratio in wear control: a nanocomposite coating approach to optimized tribological behaviour. Wear, 246 (2000) p. 1-11.

7. A. P. Tschiptschin and C. E. Pinedo, Estrutura e propriedades do aço inoxidável austenítico AISI 316L Grau ASTM F138 nitretado sob plasma à baixa temperatura. Revista Escola de Minas, 63-1 (2010) p. 137-141.

8. G. C. A. Baldin, Caracterização Frente a Corrosão dos Aços Inoxidaveis Super Duplex Endurecidos Superficialmente por Nitretação a Plasma. Trabalho de Graduação, Universidade Federal do Rio Grande do Sul, 2010.

9.R. C. Cozza, Estudo do Comportamento do Coeficiente de Desgaste e dos Modos de Desgaste Abrasivo em Ensaios de Desgaste Micro-Abrasivo, Dissertação, Universidade de São Paulo, 2006.

10. E.I. Dalibon, Tribological properties of SiNx Films on PH Stainless Steel With and Without nitriding a pre-treatment. $11^{\mathrm{a}}$ International Congress on Metallurgy \& Materials Sam/Conamet, Procedia Materials Science, 1 (2012) p. 313-320. 